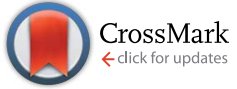

Cite this: RSC Adv., 2017, 7, 16253

Received 16th December 2016 Accepted 7th March 2017

DOI: 10.1039/c6ra28281d

rsc.li/rsc-advances

\section{Treatment with low-dose sorafenib in combination with a novel benzimidazole derivative bearing a pyrolidine side chain provides synergistic anti- proliferative effects against human liver cancer $\dagger$}

\author{
Ming-Hua Hsu, ${ }^{\text {a }}$ Shih-Ming Hsu, ${ }^{\mathrm{b}}$ Yu-Cheng Kuo, ${ }^{c}$ Chih-Yu Liu, ${ }^{d}$ Cheng-Ying Hsieh, ${ }^{\text {ae }}$ \\ Yuh-Ching Twu, ${ }^{f}$ Chung-Kwe Wang, ${ }^{g}$ Yuan-Hsi Wang ${ }^{d}$ and Yi-Jen Liao*d
}

\begin{abstract}
Hepatocellular carcinoma $(\mathrm{HCC})$ is one of the most prevalent malignancies and deadliest cancers in the world. Currently, sorafenib is the only drug that has been approved by the U.S. FDA for patients with advanced HCC. However, its improvement on patient outcomes is modest, and the median survival time is only prolonged 2-3 months. In addition, the application of sorafenib is limited because of its high cost and severe adverse side-effects. Therefore, developing more effective novel agents and reducing the dosage of sorafenib are urgently needed for HCC therapy. Here, a novel benzimidazole derivative (4a) bearing a pyrolidine side chain (9a) was synthesized. The treatments of compounds $4 a$, $9 a$ and sorafenib either alone or in combination on the inhibition of liver cancer cells proliferation were measured using alamarBlue cell viability and trypan blue staining assay. Intracellular signaling pathway activities were assessed by Western blot, Q-PCR and IHC staining. The HuH7 xenograft model was used to examine antitumor activity in vivo. Adverse effects (e.g., changes in body weight, serum parameters, liver function and pathology) of mice treated with 9a were also evaluated. Compound 9a significantly inhibited HCC cell proliferation compared with 4a. In addition, 9a strongly synergized with a low dose of sorafenib in suppressing HCC cell proliferation. Regarding the activities of the signaling pathways, sorafenib did not suppress AKT signaling; however, 9a inhibited AKT and its downstream phosphorylation of p70S6K. In addition, treatment with either $9 a$ alone or in combination with sorafenib led to the inhibition of JNK phosphorylation. However, there were no effects on the inhibition of apoptosis. The in vivo $\mathrm{HuH7}$ xenograft model showed that the administration of 9a plus a low dose of sorafenib significantly decreased expression of the HCC markers $\alpha$-fetoprotein, glypican-3 and survivin as well as suppressed tumor growth. Finally, there were no adverse effects in mice treated with 9a. In conclusion, cotreatment with a novel benzimidazole derivative bearing a pyrolidine side chain in combination with a low dose of sorafenib exerted significant antitumor activity in preclinical HCC models, which potentially suggests its use as a novel therapeutic strategy for patients with HCC.
\end{abstract}

\section{Introduction}

${ }^{a}$ Nuclear Science \& Technology Development Center, National Tsing Hua University, Hsinchu, 30013, Taiwan

${ }^{b}$ Department of Biomedical Imaging and Radiological Sciences, National Yang-Ming University, Taipei, 11221, Taiwan

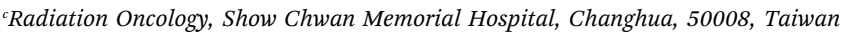
${ }^{d}$ School of Medical Laboratory Science and Biotechnology, College of Medical Science and Technology, Taipei Medical University, No. 250, Wu-Hsing Street, Taipei, 11031, Taiwan. E-mail: yjliao@tmu.edu.tw; Tel: +886-2-27361661 ext. 3333

eDepartment of Chemistry, National Tsing Hua University, Hsinchu, 30013, Taiwan ${ }^{f}$ Department of Biotechnology and Laboratory Science in Medicine, School of Biomedical Science and Engineering, National Yang-Ming University, 11221 Taipei, Taiwan

${ }^{g}$ Department of International Medicine, Taipei City Hospital Ranai Branch, Taipei, 10629, Taiwan

$\uparrow$ Electronic supplementary information (ESI) available. See DOI: 10.1039/c6ra28281d
Hepatocellular carcinoma (HCC) is the fifth most common cancer in the world and the third leading cause of cancerrelated death. ${ }^{\mathbf{1} 2}$ Traditional systemic chemotherapy does not provide survival benefits to patients with HCC. The molecular pathogenesis of HCC is very complex, as it involves different pathways and molecular aberrations. ${ }^{3,4}$ The activation of Ras/ Raf/MAPK and PI3K/AKT pathways trigger cell proliferation and survival signaling, which have been activated in various types of cancer including HCC. $^{5-7}$ Sorafenib, a multikinase inhibitor that targets tumor angiogenesis and proliferation, is the only drug approved by the U.S. Food and Drug Administration for patients with advanced HCC. ${ }^{8}$ Sorafenib blocks the serine-threonine kinases Raf-1 and B-Raf, the receptor tyrosine 
kinase of vascular endothelial growth factor receptors, and platelet-derived growth factor receptor- $\beta .{ }^{9}$ Two large-scale, phase III randomized, double-blind clinical trials, have demonstrated a survival benefit from treatment in patients with advanced HCC. ${ }^{\mathbf{1 0 1 1}}$ However, the application of sorafenib is restricted because of its high cost, incomplete effect against metastasis, and severe adverse side-effects. ${ }^{10-12}$ To date, no effective therapies are available for patients who fail to respond sorafenib. Additionally, the current acquisition cost of sorafenib is high, and its approved use by Taiwan medical insurance companies is sparing. For these reasons, reducing the dosage of sorafenib may resolve the extenuating economic burden.

Benzimidazole is a naturally occurring bicyclic compound ${ }^{\mathbf{1 3}}$ consisting of a fused benzene and imidazole ring and is an integral part of vitamin $\mathrm{B}_{12}$. Because of the structural similarities of benzimidazole with purine, they can easily interact with the other biomolecules in living systems. Therefore, this compound has considerable potential for medicinal chemistry and is a critical pharmacophore in drug discovery. ${ }^{\mathbf{1 4}}$ Benzimidazole and its derivatives possess various biological activities, including antibacterial, ${ }^{15,16}$ anti-tubercular, ${ }^{17}$ antifungal, ${ }^{18}$ antiprotozoal, ${ }^{19,20}$ anti-HIV,${ }^{21}$ anti-hepatitis viruses, ${ }^{22,23}$ and the potential to act as protein kinase inhibitors. ${ }^{24}$ Furthermore, a benzimidazole derivative small-molecule 991 has been found to act as a AMPK activator in hepatocytes and skeletal muscle. ${ }^{25,26}$ Recently, benzimidazole derived scaffolds are gaining attention in medicinal chemistry since the presence of a heterocyclic imidazole ring that offers anti-cancer potential. ${ }^{27}$ For example, methyl 2-(5-fluoro-2-hydroxyphenyl)- $1 H$-benzo[ $d]$ imidazole-5-carboxylate, a benzimidazole derivative displays greater toxicity against liver cancer and cervical cancer cells. ${ }^{28,29}$ 2-Aryl benzimidazole derivative exhibits anti-breast cancer activity by blocking EGFR and HER2 phosphorylation. ${ }^{30}$

In this study, we developed a novel benzimidazole derivative bearing a pyrolidine side chain and showed that this derivative exerts synergistic anti-liver cancer effects with a low dose of sorafenib by blocking the MAPK/ERK and PI3K/AKT signaling pathways both in vitro and in vivo.

\section{Materials and methods}

\subsection{Benzimidazole derivatives syntheses}

2.1.1. Synthesis of 1-(1H-benzo[d]imidazol-2-yl)ethan-1-ol (2). To a stirred solution of $o$-phenylenediamine (1) (4.32 g, $40.0 \mathrm{mmol}, 1.0$ equiv.) in lactic acid (3.96 g, $44.0 \mathrm{mmol}, 1.1$ equiv.) was added with hydrochloric acid $(4.0 \mathrm{~N}, 25 \mathrm{~mL})$, and the reaction mixture was heated to reflux for $16 \mathrm{~h}$. Afterwards, the reaction mixture was cooled down to room temperature and neutralized with a sodium hydroxide solution. The reaction mass was filtered to obtain compound $2(6.15 \mathrm{~g}, 38.0 \mathrm{mmol})$ as a 95\% yield of pale yellow solids: ${ }^{1} \mathrm{H}$ NMR $\left(\mathrm{CDCl}_{3}, 500 \mathrm{MHz}\right)$ $\delta 1.73\left(\mathrm{~d}, J=6.0 \mathrm{~Hz}, 3 \mathrm{H}, \mathrm{CH}_{3}\right), 5.22(\mathrm{q}, J=6.0 \mathrm{~Hz}, 1 \mathrm{H}, \mathrm{CH}), 7.26$ $(\mathrm{d}, J=6.0 \mathrm{~Hz}, 1 \mathrm{H}, \mathrm{ArCH}), 7.27$ (d, $J=5.5 \mathrm{~Hz}, 1 \mathrm{H}, \mathrm{ArCH}), 7.59$ (d, $J=5.5 \mathrm{~Hz}, 1 \mathrm{H}, \mathrm{ArCH}), 7.60(\mathrm{~d}, J=6.0 \mathrm{~Hz}, 1 \mathrm{H}, \mathrm{ArCH})$.

2.1.2. Synthesis of 1 - $(1 H$-benzo[d]imidazol-2-yl)ethan-1one (3). First, alumina-supported permanganate was prepared by mixing solid $\mathrm{KMnO}_{4}(2.0 \mathrm{~g}, 12.65 \mathrm{mmol}, 2.5$ equiv.) and solid aluminum oxide $(2.5 \mathrm{~g})$ in a mortar ground with a pestle for $3 \mathrm{~min}$. Then, compound 2 ( $810 \mathrm{mg}, 4.99 \mathrm{mmol}, 1.0$ equiv.) was added into the mortar and pestle and stirred for another $10 \mathrm{~min}$. After transferring the reaction mixture to a beaker, acetone $(40 \mathrm{~mL})$ was added and stirred for $20 \mathrm{~min}$. The mixture was filtered and the filtrate was evaporated to obtain a crude residue. The organic mass was extracted with EtOAc $(2 \times 10$ $\mathrm{mL})$, washed with $\mathrm{H}_{2} \mathrm{O}(2 \times 5.0 \mathrm{~mL})$, dried over $\mathrm{MgSO}_{4}(\mathrm{~s})$, filtered, and concentrated under reduced pressure. The residue was purified by use of column chromatography (10\% ethylacetate in hexanes as eluent) to produce the desired compound 3 (580 mg, $3.62 \mathrm{mmol}$ ) as a $72 \%$ yield of white solids: ${ }^{1} \mathrm{H}$ NMR $\left(\mathrm{CDCl}_{3}, 400 \mathrm{MHz}\right) \delta 2.81\left(\mathrm{~s}, 3 \mathrm{H}, \mathrm{CH}_{3}\right), 7.35(\mathrm{dd}, J=8.0 \mathrm{~Hz}, 1 \mathrm{H}$, $\mathrm{ArCH}), 7.41$ (dd, $J=7.5 \mathrm{~Hz}, 1 \mathrm{H}, \mathrm{ArCH}), 7.53$ (d, $J=8.0 \mathrm{~Hz}, 1 \mathrm{H}$, $\mathrm{ArCH}), 7.90$ (d, $J=8.0 \mathrm{~Hz}, 1 \mathrm{H}, \mathrm{ArCH})$.

2.1.3. Synthesis of $(E)-1-(1 H$-benzo[d]imidazol-2-yl $)-3-$ phenylprop-2-en-1-one (4a). Compound 3 (640 mg, $4.0 \mathrm{mmol}$, 1.0 equiv.) was added to benzaldehyde ( $467 \mathrm{mg}, 4.4 \mathrm{mmol}, 1.1$ equiv.) and aqueous $\mathrm{KOH}(40 \%, 2.0 \mathrm{~mL})$ in ethanol $(8.0 \mathrm{~mL})$. After workup and purification with column chromatography (15\% EtOAc in hexanes as eluant), compound 4 a (870 mg, 3.51 mmol) was obtained as an $88 \%$ yield of yellow solids: ${ }^{1} \mathrm{H}$ NMR (acetone- $\left.d_{6}, 500 \mathrm{MHz}\right) \delta 7.37(\mathrm{t}, J=7.5 \mathrm{~Hz}, 1 \mathrm{H}, \mathrm{ArCH}), 7.44(\mathrm{t}, J=$ $7.5 \mathrm{~Hz}, 1 \mathrm{H}, \mathrm{ArCH}), 7.52-7.53(\mathrm{~m}, 3 \mathrm{H}, 3 \times \mathrm{ArCH}), 7.68(\mathrm{~d}, J=$ $8.0 \mathrm{~Hz}, 1 \mathrm{H}, \mathrm{ArCH}), 7.88(\mathrm{~d}, J=7.5 \mathrm{~Hz}, 2 \mathrm{H}, 2 \times \mathrm{ArCH}), 7.88(\mathrm{~d}, J=$ $7.5 \mathrm{~Hz}, 1 \mathrm{H}, \mathrm{ArCH}), 8.03$ (d, $J=16 \mathrm{~Hz}, 1 \mathrm{H}, \mathrm{COCH}), 8.17$ (d, $J=$ $16.0 \mathrm{~Hz}, 1 \mathrm{H}, \mathrm{PhCH}$ ); ${ }^{13} \mathrm{C}$ NMR (acetone- $\left.d_{6}, 125 \mathrm{MHz}\right) \delta 113.64$, 122.45, 122.55, 124.18, 126.82, 128.97, 129.78, 130.08, 131.77, 131.91, 135.81, 144.70, 145.23, 146.01, 150.20, 181.92; IR (neat) 3357 (s), 3247 (N-H, s), 2920 (s), 2850 (s), 1661 (C=O, s), 1632 (m), 1597 (C=N, s), 1424 (s), 1331 (C-N, s), 1215 (m), $1138(\mathrm{w})$, $1089(\mathrm{w}), 971(\mathrm{w}), 741(\mathrm{w}), 721.59(\mathrm{w})$; MS (ESI) $m / z$ calculated for $\mathrm{C}_{16} \mathrm{H}_{12} \mathrm{~N}_{2} \mathrm{O}: 248.0950$, found: 248.0950 .

\subsection{Drugs treatment and the coefficient of drug interaction}

Compounds 4a and 9a were dissolved in 100\% dimethyl sulfoxide (DMSO; Sigma, St. Louis, MO, USA) and used at the concentrations indicated. Sorafenib Tosylate (purity $>98 \%$ ) was purchased from ApexBio (Houston, TX, USA) and dissolved in $100 \%$ DMSO and used at the concentrations indicated. The coefficient of drug interaction (CDI) was used to analyze effects of drug combinations. ${ }^{31,32} \mathrm{CDI}$ is calculated as follows: $\mathrm{CDI}=$ $\mathrm{AB} /(\mathrm{A} \times \mathrm{B})$. According to the absorbance of each group, $\mathrm{AB}$ is the ratio of the combination groups to control group; $\mathrm{A}$ or $\mathrm{B}$ is the ration of the single agent group to control group. Thus, CDI values less than, equal to, or greater than 1 indicates that the drugs are synergistic, additive, or antagonistic, respectively. CDI less than 0.7 indicates a significantly synergistic effect.

\subsection{Cell culture}

SK-Hep1 and HuH7 cells were cultured in Dulbecco's modified Eagle's medium (DMEM; Gibco BRL, Grand Island, NY, USA) with $10 \%$ heat-inactivated fetal bovine serum (HyClone, Logan, UT, USA), penicillin (100 $\left.\mathrm{U} \mathrm{mL}^{-1}\right)$, streptomycin $\left(100 \mu \mathrm{g} \mathrm{mL}{ }^{-1}\right)$, 
nonessential amino acids $(0.1 \mathrm{mM})$ and L-glutamine $(2 \mathrm{mM})$ in a humidified incubator with $5 \% \mathrm{CO}_{2}$.

\subsection{Cell viability assay}

Since the doubling time of HuH7 and SK-Hep1 cells are around $24 \mathrm{~h}$, we used $48 \mathrm{~h}$ treatment periods to detect the inhibitory effects of cell proliferation. For viability assays, cells $\left(2.5 \times 10^{3}\right)$ were seeded in a 96-well plate. After the indicated treatments, cell viability was measured by commercial alamarBlue ${ }^{\circledR}$ cell viability reagent (Life Technologies), which functions as a cell health indicator by using the reducing power of living cells to quantitatively measure the proliferation of cultured cells. ${ }^{33}$ The active ingredient of alamarBlue ${ }^{\circledR}$ (resazurin) is a nontoxic, cell permeable compound that is blue in color and virtually nonfluorescent. Upon entering cells, resazurin is reduced by mitochondrial FMNH2, FADH2, NADH, NADPH and cytochromes, and then synthesized highly pink fluorescent resorufin. Viable cells continuously convert resazurin to resorufin, thereby generating a quantitative measure of viability and cytotoxicity. Add $10 \mu \mathrm{L}$ alamarBlue ${ }^{\circledR}$ reagent to $100 \mu \mathrm{L}$ culture media. Incubate for 2.5 hours at $37{ }^{\circ} \mathrm{C}$ in a cell culture incubator, protected from direct light. Monitor the absorbance of alamarBlue ${ }^{\circledR}$ at $570 \mathrm{~nm}$, using $600 \mathrm{~nm}$ as a reference wavelength (normalized to the $600 \mathrm{~nm}$ value). The survival percentages were calculated by dividing the OD value of treatment groups by solvent control group. Regarding trypan blue assay, live cells possess intact cell membranes that exclude trypan blue dye, whereas dead cells do not. ${ }^{34}$ Cells $\left(2.5 \times 10^{5}\right)$ were seeded in a 6-well plate. After 24 hours treatments, live cells in each well were calculated under a light microscope (Olympus, CKX41).

\subsection{Xenograft models of HCC and drug treatment}

Female NOD/SCID mice, aged 7-8 weeks were purchased from the National Laboratory Animal Center, Taiwan. All mice were maintained on a standard chow diet (no. 5001, LabDiet, St Louis, MO) and housed in a 12 hour/12 hour light/dark cycle. 1 $\times 10^{6}$ of SK-Hep1 and HuH7 cells were injected subcutaneously into two sides of the NOD/SCID mouse. The mice were assigned randomly to four groups: (1) vehicle control, (2) low dose sorafenib (12 $\mathrm{mg} \mathrm{kg}^{-1}$, daily intraperitoneal injection), (3) 9a (4 mg $\mathrm{kg}^{-1}$, daily intraperitoneal injection), and (4) low dose sorafenib plus 9a (administered as described for single agent treatments). Tumor growth was monitored at least twice a week by using Vernier caliper measurement of the length $(L)$ and width $(W)$ of the tumor. Tumor volume (TV) was calculated as follows: TV $=$ $\left(L \times W^{2}\right) / 2$. To alleviate and minimize potential pain, suffering or distress in mice, when the tumor volume of vehicle control mice reached to $1 \mathrm{~cm}^{3}$, we will stop the monitoring at that certain time point. The protocol was reviewed and approved by the Institutional Animal Care and Use Committee of Taipei Medical University. Tumors and liver tissues were collected at the end of the experiments. The samples used in protein and RNA analyses were frozen in liquid nitrogen and stored at $-80{ }^{\circ} \mathrm{C}$, while those used in IHC staining were fixed in $10 \%$ formalin.

\subsection{Western blotting}

Cells were lysed by using lysis buffer supplemented with protease and phosphatase inhibitors. Cellular proteins $(30 \mu \mathrm{g})$ were separated by SDS-PAGE. The following antibodies used in this study were purchased from Cell Signaling (Beverly, MA, USA): caspase-3, caspase-9, phospho-, and total-AKT, p70S6K, ERK, JNK, p38. The immunoblotting signals were normalized to that for $\alpha$-tubulin (Sigma-Aldrich, St Louis, MO, USA).

\subsection{RNA extraction and real-time PCR}

Total RNA was isolated from mouse liver using TRIzol Reagent (Ambion, Carlsbad, CA, USA), according to the manufacturer's protocol. Complementary DNA was produced from cellular RNA $(2 \mu \mathrm{g})$ using a SuperScript II RNase H-Reverse Transcriptase Kit (Invitrogen, Carlsbad, CA, USA). The specific primer sequences are listed in ESI Table S1. $\dagger$ Reactions $(10 \mu \mathrm{l})$ were contained $4 \mu \mathrm{l}$ template cDNA $(20 \mathrm{ng}), 5 \mu \mathrm{l}$ KAPA SYBR® FAST qPCR Master Mix $(2 \times)$, and $1 \mu \mathrm{l}$ forward/reverse primer mix $(6 \mu \mathrm{M}$ each) (KAPA Biosystems, Boston, Massachusetts, USA). Thermal cycling consisted of $15 \mathrm{~min}$ at $95{ }^{\circ} \mathrm{C}$, followed by 40 cycles at $95{ }^{\circ} \mathrm{C}$ for $15 \mathrm{~s}$ and $60{ }^{\circ} \mathrm{C}$ for $60 \mathrm{~s}$ using the Stepone System (AppliedBiosystems, Foster City, CA, USA). The predicted cycle threshold (CT) values were exported into Excel worksheets for analysis. Comparative CT methods were used to determine the gene expression levels relative to that for GAPDH.

\subsection{Immunohistochemical staining and blood biochemical parameters}

Paraffin-embedded liver and tumor sections were incubated with the antibodies against PCNA and Ki-67 (GenScript, Piscataway, NJ, USA) and detected using the Universal LSABTM2 kit (DakoCytomation Carpinteria, CA, USA) according to the manufacturer's instructions. Serum alanine aminotransferase (ALT), gammaglutamytransferase (GGT), albumin, blood urea nitrogen (BUN), L-lactate dehydrogenase (LDH), alkaline phosphatase (ALKP), total bilirubin (TBIL), cholesterol, and triglyceride values were measured with a biochemical analyzer (VetTest ${ }^{\mathrm{TM}}$, IDEXX, USA).

\subsection{Statistical analysis}

Data from cell studies were evaluated by non-parametric tests. For this purpose, Mann-Whitney U test was used to compare two independent groups. Kruskal-Wallis followed by Bonferroni posthoc analyses was used to account for multiple testing. Data from animal studies were evaluated by parametric tests. For this purpose, a two-way analysis of variance was used to make multiple comparisons. SPSS v20.0 (SPSS Inc, Chicago, IL) was used for analysis. Differences were considered statistically significant at $p<0.05$.

\section{Results}

\subsection{The synthesis of the benzimidazole derivatives}

As shown in Fig. 1, the chemicals and conditions used are as follows: (i) glycolic acid (1.1 equiv.), $4 \mathrm{~N} \mathrm{HCl}$, reflux, $6 \mathrm{~h}$; (ii) permanganate ( 2.5 equiv.), solid aluminum oxide, solvent free, 




Fig. 1 Synthesis of a benzimidazole derivative bearing a pyrolidine side chain.

room temperature, $10 \mathrm{~min}$; (iii) benzaldehyde, $40 \% \mathrm{KOH}$, ethanol, room temperature, $10 \mathrm{~min}$; (iv) 1-(2-chloroethyl)pyrrolidine, potassium carbonate, acetonitrile, reflux, overnight. The ${ }^{1} \mathrm{H}$ and ${ }^{13} \mathrm{C}-\mathrm{NMR}$ spectra of compound 4a and 9a with their structures are shown in ESI Fig. S1.†

\subsection{Compound 9a showed more anti-proliferative effects than $4 a$ in liver cancer cells}

Compared to the DMSO control, treatment with compound $4 \mathbf{a}$ did not affect cell viability in HuH7 and SK-Hep1 cells after a $48 \mathrm{~h}$ exposure to the drugs (Fig. 2A). However, compound 9a significantly reduced cell proliferation by $30-40 \%$ compared with compound 4a (Fig. 2A). Although 4a treatment showed a slightly inhibitory trend in cell proliferation, 9a exerted more significant inhibition of cell proliferation in both HuH7 and SKHep1 cells in a dose-dependent manner (Fig. 2B). These data suggest that compound 9a can significantly reduce liver cancer cell proliferation compared with compound $\mathbf{4 a}$.

\subsection{The combination of compound 9a with a low dose of sorafenib synergistically inhibits liver cancer cell proliferation}

Since the cost of sorafenib is prohibitive for clinical treatments, reducing the dosage of sorafenib may resolve the extenuating economic burden. We next examined whether the combination of compound 9a with a low dose of sorafenib can additively inhibit liver cancer cell proliferation. As shown in Fig. 2C, treatment with clinically relevant concentrations of sorafenib (up to $10 \mu \mathrm{M}$ ) for $48 \mathrm{~h}$ reduced $40 \%$ of the cell proliferation. Meanwhile, low doses of sorafenib (5 $\mu \mathrm{M}$ and $2.5 \mu \mathrm{M})$ only inhibited $10-20 \%$ of the proliferation of both HuH7 and SKHep1 cells. Notably, compound 9a (at $50 \mu \mathrm{M}$ ) and low doses of sorafenib (at $5 \mu \mathrm{M}$ and $2.5 \mu \mathrm{M}$ ) in combination exerted increased $20-30 \%$ of anti-proliferative effects compared to low

Table $1 \mathrm{CDI}$ of the combination of sorafenib and compound $9 \mathrm{a}$ in HuH7 and SK-Hep1 cells

\begin{tabular}{|c|c|c|c|c|c|}
\hline & & \multicolumn{2}{|c|}{$\mathrm{HuH7}$} & \multicolumn{2}{|c|}{ SK-Hep1 } \\
\hline & & \multicolumn{4}{|c|}{ 9a $(\mu \mathrm{M})$} \\
\hline & & 25 & 50 & 25 & 50 \\
\hline \multirow[t]{4}{*}{ Sorafenib $(\mu \mathrm{M})$} & 2.5 & 0.98 & 0.75 & 0.81 & 0.58 \\
\hline & 5 & 0.94 & 0.76 & 0.79 & 0.56 \\
\hline & 10 & 0.85 & 0.76 & 0.83 & 0.61 \\
\hline & 20 & 0.87 & 0.82 & 0.89 & 0.74 \\
\hline
\end{tabular}

(A)
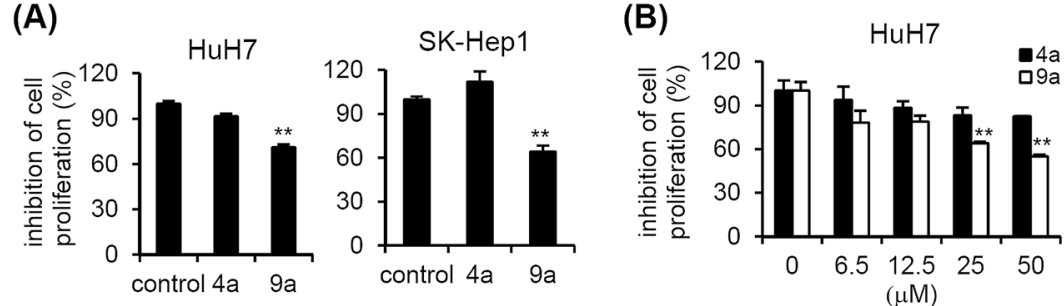

(C)

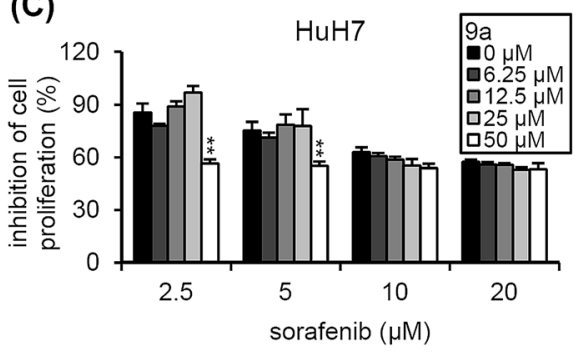



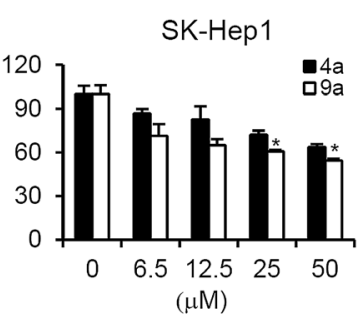

(D)

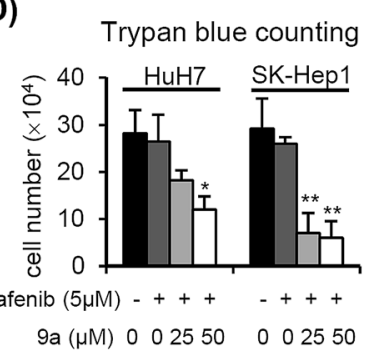

Fig. 2 Anti-proliferative effects of compounds 4a and 9a in liver cancer cells. (A) HuH7 and SK-Hep1 cells were exposed to DMSO control, 4a, or $9 \mathrm{a}$ at $50 \mu \mathrm{M}$ for $48 \mathrm{~h}$ and cell proliferation was assessed using an alamarBlue assay kit. **, $p<0.01$ vs. DMSO control. (B) Dose-dependent inhibition of $4 a$ and $9 a$ on cell proliferation in Huh7 and SK-Hep1 cells. $*, p<0.05$ vs. $4 a$. $* *, p<0.01$ vs. $4 a$. (C) Effect of the combination of sorafenib and $9 \mathrm{a}$ on the proliferation of liver cancer cells. (D) Cell numbers were determined by trypan blue counting. *, $p<0.05 \mathrm{vs.} 0 \mu \mathrm{M}$. **, $p<$ $0.01 \mathrm{vs} .0 \mu \mathrm{M}$. The data are expressed as the mean \pm SD. Each experiment was performed in three independent replicates, and a similar phenomenon was observed among the replicates. Therefore, the representative data are shown in the figure. 

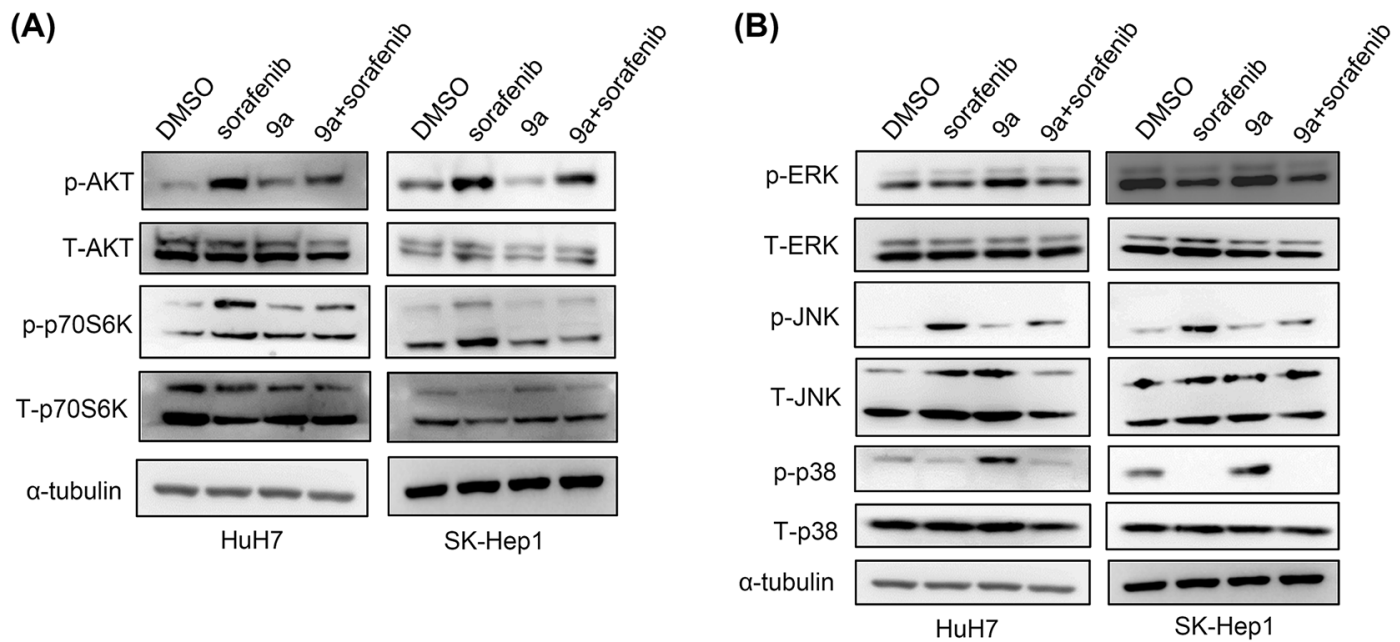

Fig. 3 Effects of either individual or in combination treatments of compound 9a and a low dose of sorafenib on the AKT and MAPK signaling pathways. (A) Western blot analysis of AKT and p70S6K phosphorylation in Huh7 and SK-Hep1 cells treated with DMSO control, sorafenib (5 $\mu$ M), 9a $(12.5 \mu \mathrm{M})$, and 9a + sorafenib for $48 \mathrm{~h}$. (B) Western blot analysis of ERK, JNK, and p38 phosphorylation in Huh7 and SK-Hep1 cells treated with DMSO control, sorafenib $(5 \mu \mathrm{M}), 9 \mathrm{a}(12.5 \mu \mathrm{M})$, and $9 \mathrm{a}+$ sorafenib for $48 \mathrm{~h}$. Each experiment was performed in three independent replicates, and a similar phenomenon was observed among the replicates. Therefore, the representative data are shown in the figure.

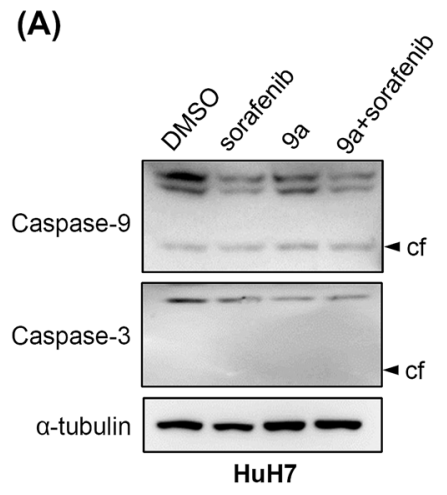

(C)
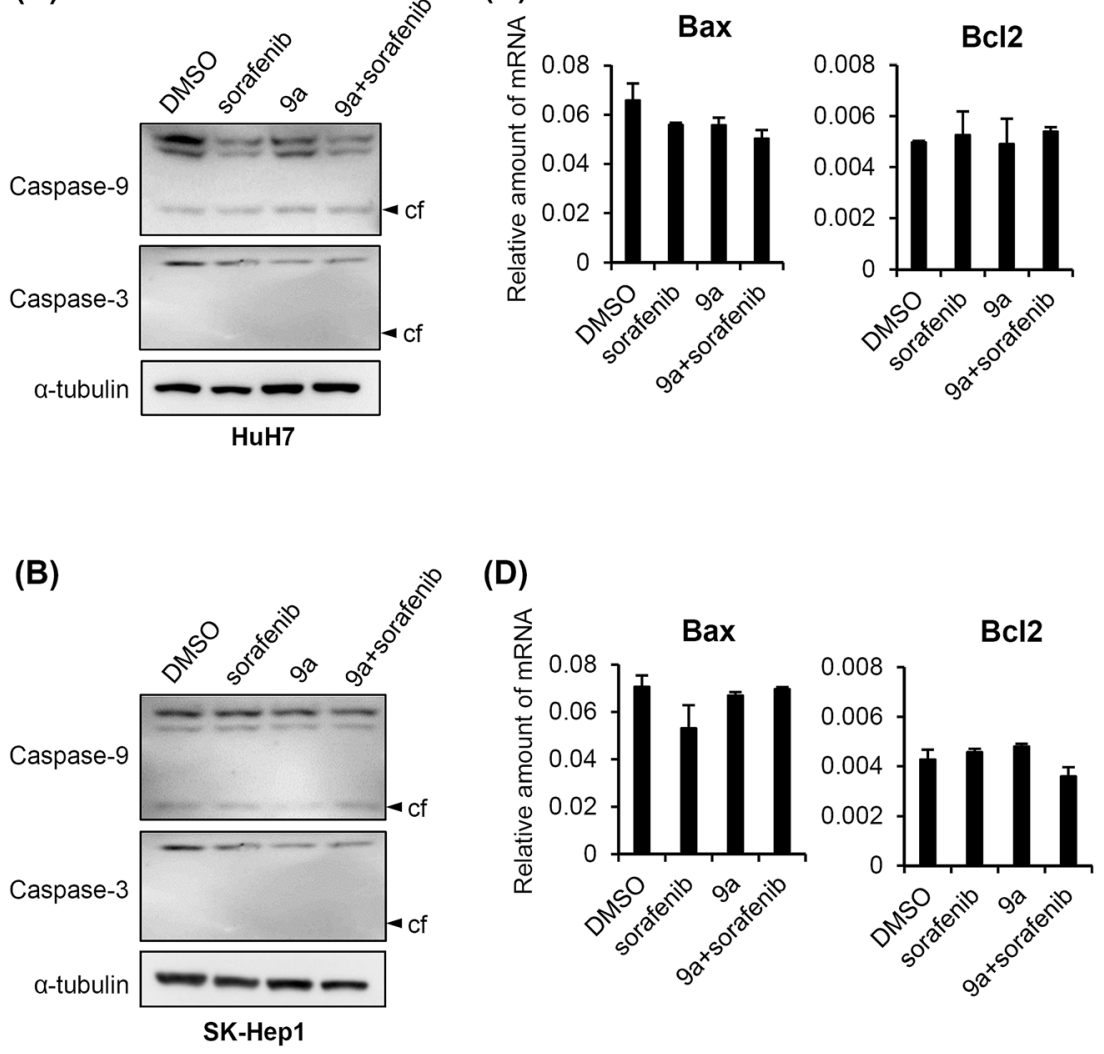

Fig. 4 Effects of individual and combination treatments of compound 9a and low dose of sorafenib on the apoptosis pathway. (A and B) Western blot analysis of caspase- 9 and caspase- 3 cleavage in Huh7 and SK-Hep1 cells treated with DMSO control, sorafenib $(5 \mu \mathrm{M}), 9 a(12.5 \mu \mathrm{M})$, and 9a + sorafenib for $48 \mathrm{~h}$ (C and D) Q-PCR analysis of Bax and Bcl2 expression in Huh7 and SK-Hep1 cells treated with DMSO control, sorafenib (5 $\mu$ M), 9a $(12.5 \mu \mathrm{M})$, and $9 \mathrm{a}+$ sorafenib for $48 \mathrm{~h}$. The data are expressed as the mean \pm SD. Each experiment was performed in three independent replicates, and a similar phenomenon was observed among the replicates. Therefore, the representative data are shown in the figure. 
(A)

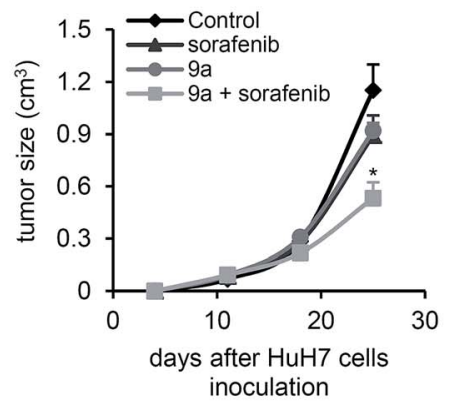

(B)


(C)

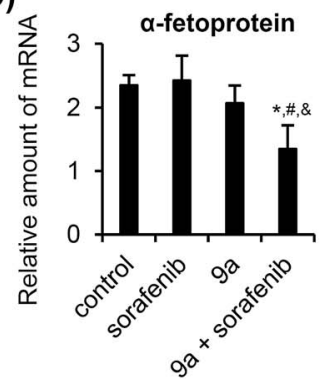

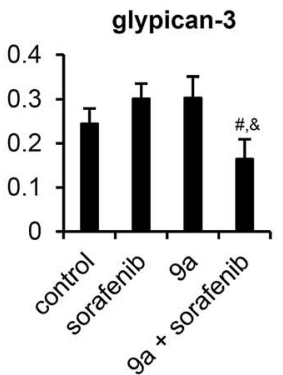

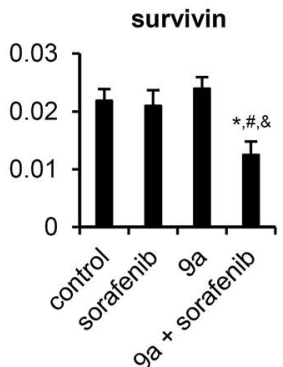

Fig. 5 The antitumor effect of compound 9a plus a low dose of sorafenib in a xenograft model. (A) Effects of vehicle control, sorafenib, 9a, and $9 \mathrm{a}+$ sorafenib administration on $\mathrm{HuH7}$ xenograft tumor growth rates ( $n=4$ per group). The mean tumor volume \pm s.e.m. at the indicated time is shown. (B) Images of subcutaneous tumor from each treatment group when the mice were sacrificed. (C) Q-PCR analysis of three human HCC markers (glypican-3, survivin, and $\alpha$-fetoprotein) in HuH7 xenograft tumors ( $n=4$ per group). The data are expressed as the mean \pm s.e.m. $*, p<$ 0.05 vs. vehicle control. ${ }^{\#}, p<0.05$ vs. sorafenib alone. ${ }^{\S}, p<0.05$ vs. $9 a$ alone.

doses of sorafenib in HuH7 cells (Fig. 2C). In SK-Hep1 cells, the significant inhibitory effects on the cell viability were also observed in the combination of compound $9 \mathrm{a}$ (at $25 \mu \mathrm{M}$ and 50 $\mu \mathrm{M})$ and low doses of sorafenib (Fig. 2C). By trypan blue counting assay, the similar synergistic inhibitory effects on the viability of HuH7 and SK-Hep1 cells were also observed in the combination of compound 9a and low doses of sorafenib (Fig. 2D). Our data indicate that this increased anti-proliferative activity of compound 9a was not a cell line-specific effect. CDI was used to determine the type of interaction between the agents (Table 1). In SK-Hep1 cells, $50 \mu \mathrm{M}$ of compound 9a had a significantly synergistic effect with $2.5 \mu \mathrm{M}$ and $5 \mu \mathrm{M}$ sorafenib (CDI, 0.58 and 0.56, respectively). The similar result was observed with the combined usage of $9 \mathrm{a}(50 \mu \mathrm{M})$ and low doses of sorafenib $(2.5 \mu \mathrm{M}$ and $5 \mu \mathrm{M})$ in $\mathrm{HuH7}$ cells (CDI, 0.75 and 0.76 , respectively). These data imply that compound 9a was strongly synergistic with a low dose of sorafenib in suppressing HCC cells proliferation.

\subsection{The combination of low-dose sorafenib and compound 9a inhibits AKT/p70S6K signaling}

The MAPK and AKT signaling cascades are two major pathways activated in the development of HCC. ${ }^{35}$ To gain insights into the mechanisms underlying the synergistic anti-proliferative effect of the 9a and sorafenib combination in both $\mathrm{HuH7}$ and SKHep1 cells, we examined whether the combination treatment regulated the MAPK and AKT pathways affected by each agent alone. The Western blot showed that sorafenib did not inhibit


$9 a+$ sorafenib
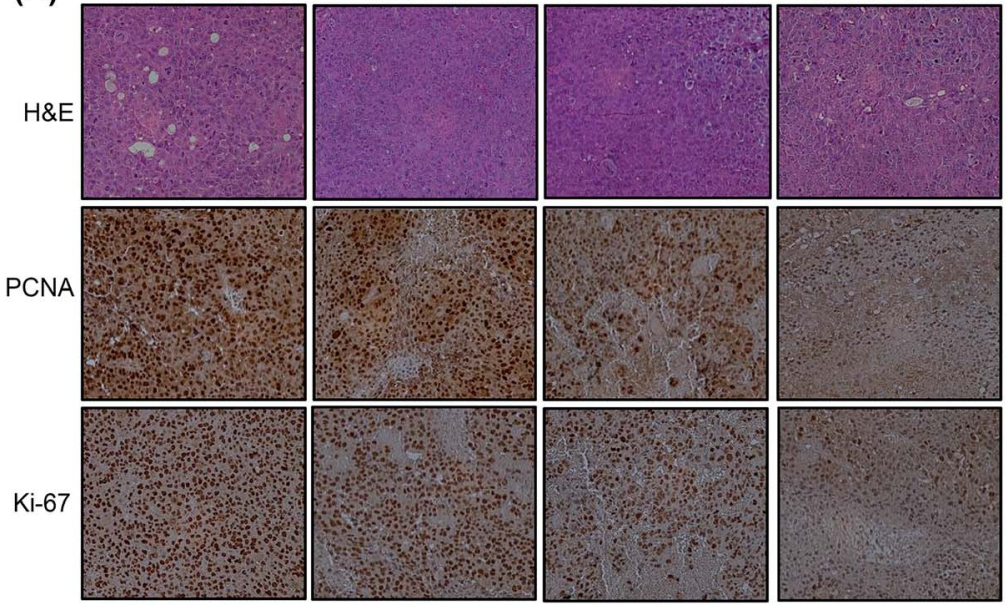

(B)

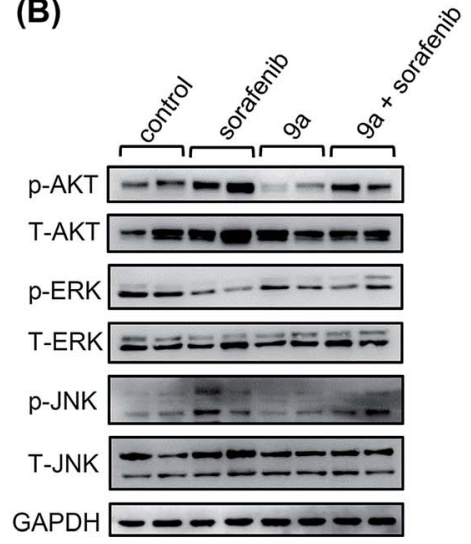

Fig. 6 Anti-proliferative effect of compound 9a and a low dose of sorafenib in HuH7 xenograft tumors. (A) Representative IHC image of Ki-67 and PCNA staining in HuH7 xenograft tumors. (B) Representative Western blot analysis of AKT, ERK, and JNK in HuH7 xenograft tumors ( $n=4$ per group). The data are expressed as the mean \pm s.e.m. 
(A)

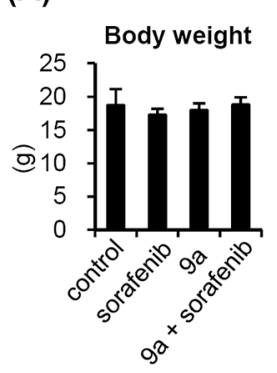

(C)

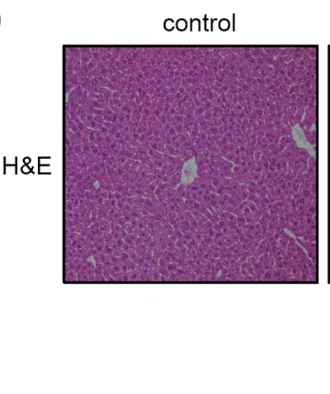

sorafenib

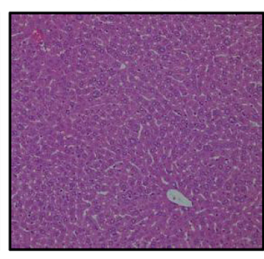

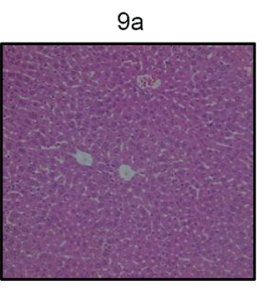



(B)
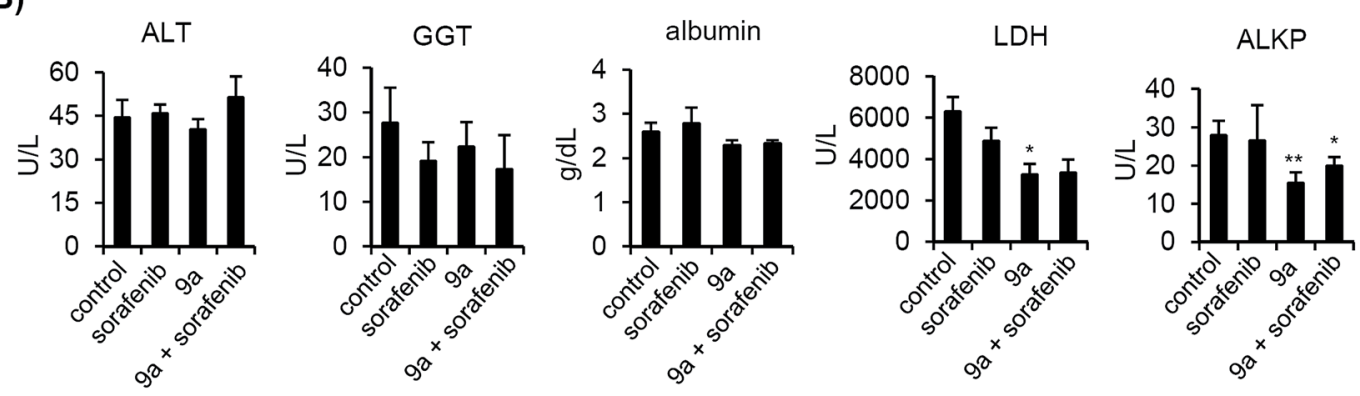

TBIL


BUN

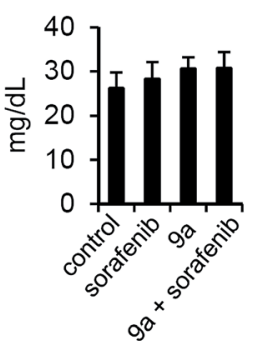

(D)


apoptosis

lipogenesis
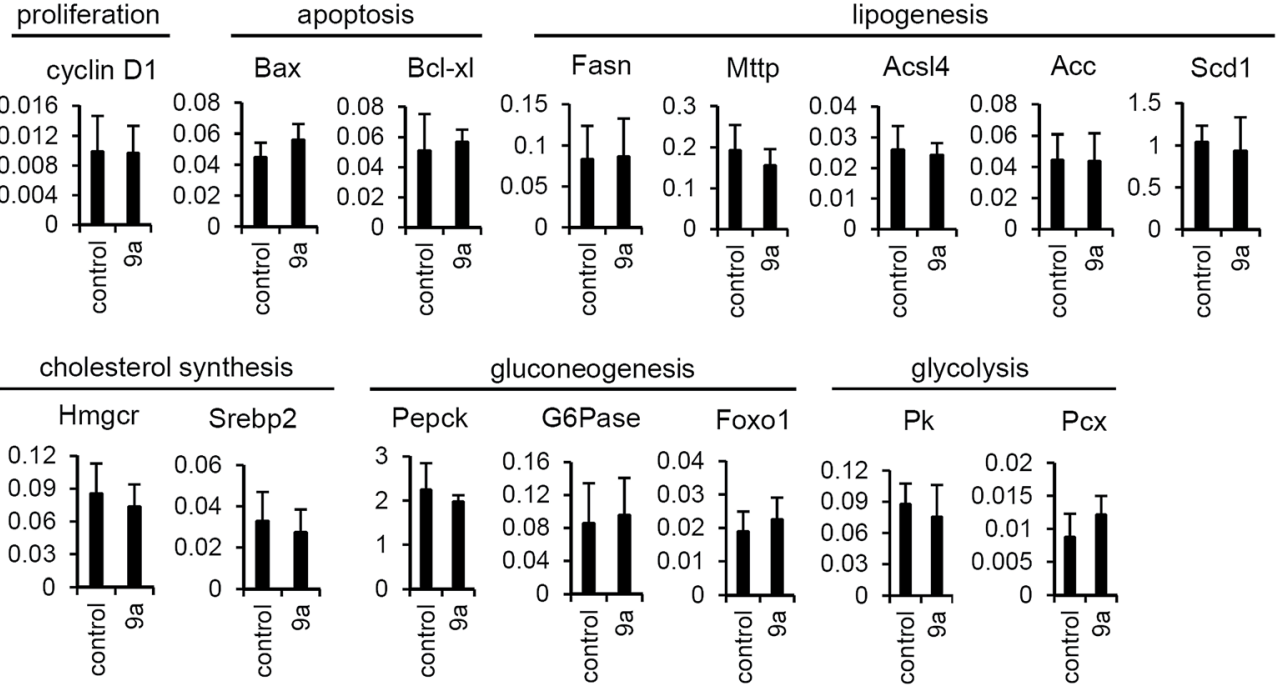

gluconeogenesis


Fig. 7 Adverse effects of compound 9a administration in mice. (A) Mouse body weight and (B) serum samples were collected at the end of the experiment, and the ALT, GGT, albumin, LDH, ALKP, BUN, TBIL, cholesterol, and triglyceride values were assessed. (C) H\&E staining of liver tissues from euthanized mice from each treatment group. (D) Q-PCR analysis of hepatic proliferation marker (cyclin D1), apoptosis markers (Bax and $\mathrm{Bcl}-\mathrm{xl}$ ), lipogenesis markers (Fasn, Mttp, Acsl4, Acc, and Scd1), cholesterol synthesis markers (Hmgcr and Srebp2), gluconeogenesis markers (Pepck. G6Pase, and Foxo1), and glycolysis markers (Pk and Pcx) in vehicle control and 9a treated mice $(n=4$ per group). The data are expressed as the mean \pm s.e.m. 
either AKT or p70S6K activation (Fig. 3A). Notably, compound 9a alone decreased the phosphorylation of AKT and p70S6K in both HuH7 and SK-Hep1 cells (Fig. 3A). Regarding the MAPK pathway, sorafenib inhibits the phosphorylation of ERK1/2 and p38 but not JNK (Fig. 3B). Importantly, 9a significantly inhibited JNK activation in both HuH7 and SK-Hep1 cells (Fig. 3B).

\subsection{Co-treatment with compound 9a and sorafenib does not affect apoptotic cell death}

Next, we examined whether compound 9a inhibited cell growth by inducing apoptosis signaling. As shown in Fig. 4A and B, 9a treatment did not promote the cleavage of caspase- 3 and caspase-9 in both HuH7 and SK-Hep1 cells. The mRNA levels of the pro-apoptotic gene Bax and the anti-apoptotic gene $\mathrm{Bcl} 2$ were unchanged in the 9a-treated groups (Fig. 4C and D). These data suggest that the suppression of HCC cell proliferation in compound 9a-treated cells arises primarily from inhibiting cell proliferation via the AKT/p70S6K signaling pathway rather than inducing the apoptosis pathway.

\subsection{The antitumor effect of compound 9a plus a low dose of sorafenib in a HuH7 xenograft model}

To evaluate whether the synergistic effect of 9a plus low-dose sorafenib could be clinically relevant, we next examined the antitumor activity of this co-treatment in NOD/SCID mice bearing established HuH7 tumor xenografts. As shown in Fig. 5A and B, neither low-dose sorafenib nor compound 9a alone significantly suppressed tumor growth. Notably, treatment of mice with the combination of 9a plus low-dose sorafenib significantly reduced the growth of the $\mathrm{HuH7}$ tumor (Fig. 5A and B). Real-time PCR was used to analyze the mRNA levels $\alpha$-fetoprotein, glypican-3 and survivin, all of which have been described as hepatic markers for HCC. ${ }^{36}$ Compared with vehicle control, sorafenib, or 9a treatment alone, the HuH7 tumors from mice treated with 9a plus sorafenib expressed significantly lower levels of all three HCC markers (Fig. 5C). These data indicate that this combination treatment strategy (9a plus low-dose sorafenib) causes synergistic tumor growth inhibition in vivo.

\subsection{Compound 9a plus low-dose sorafenib inhibits xenograft tumor proliferation by downregulating AKT/p70S6K signaling}

To further correlate the in vivo antitumor effects with the mechanisms identified in vitro, intratumoral biomarkers were assessed by IHC and Western blot analyses. As shown in Fig. 6A, the combined treatment markedly reduced the immunostaining levels of PCNA and Ki-67 nuclear signal compared to the control groups, which is indicative of reduced $\mathrm{HuH7}$ tumor proliferation. Consistent with our in vitro data, 9a alone significantly inhibited the phosphorylation of AKT and JNK in HuH7 xenograft tumors (Fig. 6B). In addition, co-treatment of 9a and low-dose sorafenib markedly downregulated AKT and JNK phosphorylation compared to low-dose sorafenib alone (Fig. 6B). Accordingly, the combination treatment exerted a greater anti-proliferative effect than either single agent alone in $\mathrm{HuH} 7$ xenografts in vivo.

\subsection{Compound 9a administration did not induce adverse effects on mice}

To assess the in vivo toxicities mediated by either 9a alone or the co-treatment of 9a plus sorafenib, the mouse body weight was measured, and results showed that there was no difference among the various groups (Fig. 7A). Meanwhile, at the end of the experiments, the serum was collected, and the liver function (ALT, GGT, albumin, LDH, ALKP, TBIL, cholesterol and triglyceride), and kidney function (BUN) values were analyzed. As shown in Fig. 7B, the serum values of ALT, GGT, albumin, TBIL, cholesterol, triglyceride and BUN were no significant differences as compared to the vehicle-treated groups. Another two liver function markers (LDH and ALKP) even more lower in compound 9a treated mice than control mice. Histological liver section staining with H\&E (Fig. 7C) showed no hepatic damage among the various groups. In addition, the expression of hepatic proliferation and apoptosis related genes (cyclin D1, Bax, and Bcl-xl) were no difference between control and 9a treated mice (Fig. 7D). Since liver plays a critical role in lipids and glucose metabolism, ${ }^{37,38}$ we further investigate whether compound 9a treatment altered the hepatic lipids and glucose regulatory genes expression. As shown in Fig. 7D, fatty acid synthase (Fasn), microsomal triglyceride transfer protein (Mttp), long-chain fatty-acid-CoA ligase-4 (Ascl4), stearoyl-CoA desaturase 1 (Scd1), and acetyl-CoA carboxylase (Acc), which are genes involved in de novo lipogenesis, did not differ between control and 9a treated mice. Besides, there were no changes in two cholesterol synthesis genes: 3-hydroxy-3-methyl-glutarylcoenzyme A reductase (Hmgcr) and sterol response element binding protein 2 (Srebp2) expression between control and 9a treated mice (Fig. 7D). Regarding glucose metabolic related genes, 9a treatment did not alter the expression of three gluconeogenesis regulatory genes (Pepck. G6Pase, and Foxo1) and two glycolysis regulatory genes ( $\mathrm{Pk}$ and $\mathrm{Pcx}$ ) compared with control mice (Fig. 7D). These data imply that the mice tolerated all of the treatments without presenting any overt signs of toxicity. Taken together, these data demonstrate that the in vivo efficacious dose of 9a plus sorafenib treatment against human HCC tumor growth in nude mice had no apparent signs of toxicity and liver dysfunction.

\section{Discussion}

HCC is a complex and heterogeneous tumor with aberrant activation of several signaling pathways. ${ }^{35}$ Thus, combination therapies that target multiple nodes would be more appropriate and may increase therapeutic efficacy. ${ }^{39}$ Sorafenib is the standard of treatment in the first-line setting for advanced HCC patients, but the current acquisition cost of sorafenib is high. Combined treatments of sorafenib with other agents such as erlotinib, everolimus, SC-49, rapamycin, HDAC inhibitor, PI-103 are also being investigated. ${ }^{\mathbf{4 0 - 4 6}}$ However, the clinically relevant concentrations of sorafenib used in their studies were high. 




Fig. 8 Proposed mechanisms by which compound 9a coordinates with sorafenib to inhibit liver tumor proliferation.

Therefore, decreasing the dosage of sorafenib and combining sorafenib with another agent to inhibit multiple signaling pathways involved in HCC is urgently needed.

It had been reported that several hybrid benzimidazolylchalcone derivatives bear anthelmintic, ${ }^{47}$ antifungal ${ }^{48}$ and antitumor activities. ${ }^{49}$ Benzimidazolyl curcumin mimetics possess anticancer activity, and it was hypothesized that the increments in inhibitory potency are due to the attached benzimidazole functionalities. ${ }^{50}$ Refaat $e t$ al. designed benzylidene cyanomethylbenzimidazole (ESI Fig. S2, $\dagger$ compound 1), which has excellent potential in anticancer activity against human liver carcinoma (HepG2) cell line..$^{51}$ Azam et al. reported that phenyl-benzimidazole analogues (ESI Fig. S2, $\uparrow$ compound 2) possess potent anti-cancer activity against five human cancers cell. ${ }^{52}$ Regarding the differences of the pyrrolidine derivatives compared to published derivatives are referred to some studies. Results showed that the alkylation of the $\mathrm{NH}$ group of the benzimidazole may have some novel biological activities. These benzimidazole derivatives can serve as antagonists of the chemokine receptor CXCR3 (ESI Fig. S2, $\dagger$ compound 3), ${ }^{53}$ inhibitors of hepatitis B virus (ESI Fig. S2, $\uparrow$ compound 4), ${ }^{23}$ and inhibitors of Francisella tularensis enoylACP reductase (ESI Fig. S2, $\dagger$ compound 5$)^{54}$ as well as bear antitumor activities by modifying some of the monomers on benzimidazole (ESI Fig. S2, $\dagger$ compound 6) ${ }^{55}$ In 2008, Hwu et al. modified the nordihydroguaiaretic acid (NDGA) with the nitrogen-containing five- or six-membered ring. Their derivatives can keep stable in aqueous medium, also the pyrrolidine and piperidine containing NDGAs (ESI Fig. S2, $\dagger$ compound 7-8) also show superior biological results against to HIV in human epithelial cells. ${ }^{56} O$-Alkylation of nordihydroguaiaretic acids show good results to anti-HIV, it also can react with hydrochloric acid to form salts that can significantly increasing the water solubility. We follow this idea to make the $N$-alkylation of benzimidazole and tried to explore that whether if it can possess analogous biological effect. Herein, we demonstrated that this novel benzimidazole derivative bearing a pyrolidine side chain exerts a synergistic anti-HCC effect with a low dose of sorafenib and without the adverse events of body weight loss, hepatotoxicity and liver dysfunction.

The activation of the Ras/Raf/MAPK and PI3K/AKT signaling cascades have been implicated in the pathogenesis of HCC. ${ }^{39}$ Sorafenib has been shown to inhibit tumor cell proliferation by blocking the Ras/Raf/MAPK pathway; however, sorafenib does not directly inhibit the PI3K/AKT pathway. In the present study, we developed a novel benzimidazole derivative bearing a pyrolidine side chain and examined in vitro and in vivo whether the combinations of low-dose sorafenib and this benzimidazole derivative have more potent antitumor effects than sorafenib alone. We showed that the combination of compound 9a and a low dose of sorafenib produce stronger antitumor effects on HCC than either 9a or sorafenib alone. In particular, 9a can inhibit the activation of AKT and its downstream p70S6K (Fig. 3 and $6 \mathrm{~B}$ ). Our data proposed that this combination treatment inhibited HCC cell proliferation by blocking the MAPK/ERK and AKT/P70S6K signaling pathways (Fig. 8).

\section{Conclusion}

Our study showed that the combination of a low dose of sorafenib plus a benzimidazole derivative is a potent anti-HCC therapy and that their application in combination has significant advantages compared with mono-drug therapies in inhibiting the pivotal MAPK/ERK and AKT/p70S6K proliferation pathways in HCC.

\section{Conflict of interest}

The authors declare no competing financial interest.

\section{Acknowledgements}

This study was partially supported by a grant from the Ministry of Science and Technology of the Republic of China (MOST 1032320-B-038-044).

\section{References}

1 H. B. El-Serag and K. L. Rudolph, Gastroenterology, 2007, 132, 2557-2576.

2 R. Siegel, D. Naishadham and A. Jemal, Ca-Cancer J. Clin., 2013, 63, 11-30.

3 R. N. Aravalli, E. N. Cressman and C. J. Steer, Arch. Toxicol., 2013, 87, 227-247.

4 R. N. Aravalli, C. J. Steer and E. N. Cressman, Hepatology, 2008, 48, 2047-2063.

5 I. Vivanco and C. L. Sawyers, Nat. Rev. Cancer, 2002, 2, 489501.

6 A. S. Dhillon, S. Hagan, O. Rath and W. Kolch, Oncogene, 2007, 26, 3279-3290.

7 E. F. Wagner and A. R. Nebreda, Nat. Rev. Cancer, 2009, 9, 537-549. 
8 J. Bruix, M. Sherman and D. American, Association for the Study of Liver, Hepatology, 2011, 53, 1020-1022.

9 S. M. Wilhelm, C. Carter, L. Tang, D. Wilkie, A. McNabola, H. Rong, C. Chen, X. Zhang, P. Vincent, M. McHugh, Y. Cao, J. Shujath, S. Gawlak, D. Eveleigh, B. Rowley, L. Liu, L. Adnane, M. Lynch, D. Auclair, I. Taylor, R. Gedrich, A. Voznesensky, B. Riedl, L. E. Post, G. Bollag and P. A. Trail, Cancer Res., 2004, 64, 7099-7109.

10 A. L. Cheng, Y. K. Kang, Z. Chen, C. J. Tsao, S. Qin, J. S. Kim, R. Luo, J. Feng, S. Ye, T. S. Yang, J. Xu, Y. Sun, H. Liang, J. Liu, J. Wang, W. Y. Tak, H. Pan, K. Burock, J. Zou, D. Voliotis and Z. Guan, Lancet Oncol., 2009, 10, 25-34.

11 J. M. Llovet, S. Ricci, V. Mazzaferro, P. Hilgard, E. Gane, J. F. Blanc, A. C. de Oliveira, A. Santoro, J. L. Raoul, A. Forner, M. Schwartz, C. Porta, S. Zeuzem, L. Bolondi, T. F. Greten, P. R. Galle, J. F. Seitz, I. Borbath, D. Haussinger, T. Giannaris, M. Shan, M. Moscovici, D. Voliotis, J. Bruix and S. I. S. Group, N. Engl. J. Med., 2008, 359, 378-390.

12 T. Yau, P. Chan, K. K. Ng, S. H. Chok, T. T. Cheung, S. T. Fan and R. T. Poon, Cancer, 2009, 115, 428-436.

13 L. B. Townsend and D. S. Wise, Parasitol. Today, 1990, 6, 107-112.

14 D. W. Woolley, J. Biol. Chem., 1944, 152, 225-232.

15 X. J. Fang, P. Jeyakkumar, S. R. Avula, Q. Zhou and C. H. Zhou, Bioorg. Med. Chem. Lett., 2016, 26, 2584-2588.

16 M. Tuncbilek, T. Kiper and N. Altanlar, Eur. J. Med. Chem., 2009, 44, 1024-1033.

17 R. V. Shingalapur, K. M. Hosamani and R. S. Keri, Eur. J. Med. Chem., 2009, 44, 4244-4248.

18 H. Z. Zhang, G. L. Damu, G. X. Cai and C. H. Zhou, Eur. J. Med. Chem., 2013, 64, 329-344.

19 D. Valdez-Padilla, S. Rodriguez-Morales, A. HernandezCampos, F. Hernandez-Luis, L. Yepez-Mulia, A. TapiaContreras and R. Castillo, Bioorg. Med. Chem., 2009, 17, 1724-1730.

20 F. Hernandez-Luis, A. Hernandez-Campos, R. Castillo, G. Navarrete-Vazquez, O. Soria-Arteche, M. HernandezHernandez and L. Yepez-Mulia, Eur. J. Med. Chem., 2010, 45, 3135-3141.

21 S. M. Rida, S. A. M. El-Hawash, H. T. Y. Fahmy, A. A. Hazzaa and M. M. M. El-Meligy, Arch. Pharmacal Res., 2006, 29, 826833.

22 T. Vausselin, K. Seron, M. Lavie, A. A. Mesalam, M. Lemasson, S. Belouzard, L. Feneant, A. Danneels, Y. Rouille, L. Cocquerel, L. Foquet, A. R. Rosenberg, C. Wychowski, P. Meuleman, P. Melnyk and J. Dubuisson, J. Virol., 2016, 90, 8422-8434.

23 Y. Luo, J. P. Yao, L. Yang, C. L. Feng, W. Tang, G. F. Wang, J. P. Zuo and W. Lu, Bioorg. Med. Chem., 2010, 18, 5048-5055.

24 P. Singla, V. Luxami and K. Paul, RSC Adv., 2014, 4, 1242212440.

25 M. Johanns, Y. C. Lai, M. F. Hsu, R. Jacobs, D. Vertommen, J. Van Sande, J. E. Dumont, A. Woods, D. Carling, L. Hue, B. Viollet, M. Foretz and M. H. Rider, Nat. Commun., 2016, 7, 10856.
26 L. Bultot, T. E. Jensen, Y. C. Lai, A. L. Madsen, C. Collodet, S. Kviklyte, M. Deak, A. Yavari, M. Foretz, S. Ghaffari, M. Bellahcene, H. Ashrafian, M. H. Rider, E. A. Richter and K. Sakamoto, Am. J. Physiol.: Endocrinol. Metab., 2016, 311, E706-E719.

27 G. Yadav and S. Ganguly, Eur. J. Med. Chem., 2015, 97, 419443.

28 X. Dai, L. Wang, A. Deivasigamni, C. Y. Looi, C. Karthikeyan, P. Trivedi, A. Chinnathambi, S. A. Alharbi, F. Arfuso, A. Dharmarajan, B. C. Goh, K. M. Hui, A. P. Kumar, M. R. Mustafa and G. Sethi, Oncotarget, 2017, DOI: 10.18632/oncotarget.14606.

29 M. Hasanpourghadi, C. Karthikeyan, A. K. Pandurangan, C. Y. Looi, P. Trivedi, K. Kobayashi, K. Tanaka, W. F. Wong and M. R. Mustafa, J. Exp. Clin. Cancer Res., 2016, 35, 58.

30 B. Chu, F. Liu, L. Li, C. Ding, K. Chen, Q. Sun, Z. Shen, Y. Tan, C. Tan and Y. Jiang, Cell Death Dis., 2015, 6, e1686. 31 T. C. Chou and P. Talalay, Adv. Enzyme Regul., 1984, 22, 2755.

32 S. S. Cao and Y. S. Zhen, Cancer chemotherapy and pharmacology, 1989, 24, 181-186.

33 J. O'Brien, I. Wilson, T. Orton and F. Pognan, Eur. J. Biochem., 2000, 267, 5421-5426.

$34 \mathrm{~W}$. Strober, Current protocols in immunology, 2015, 111, A3B1-A3B3.

35 S. Whittaker, R. Marais and A. X. Zhu, Oncogene, 2010, 29, 4989-5005.

36 J. M. Llovet, Y. Chen, E. Wurmbach, S. Roayaie, M. I. Fiel, M. Schwartz, S. N. Thung, G. Khitrov, W. Zhang, A. Villanueva, C. Battiston, V. Mazzaferro, J. Bruix, S. Waxman and S. L. Friedman, Gastroenterology, 2006, 131, 1758-1767.

37 L. P. Bechmann, R. A. Hannivoort, G. Gerken, G. S. Hotamisligil, M. Trauner and A. Canbay, J. Hepatol., 2012, 56, 952-964.

38 F. R. Maxfield and I. Tabas, Nature, 2005, 438, 612-621.

39 J. M. Llovet and J. Bruix, Hepatology, 2008, 48, 1312-1327.

40 M. Kudo, World J. Gastroenterol., 2012, 18, 6005-6017.

41 K. F. Chen, H. L. Chen, C. W. Shiau, C. Y. Liu, P. Y. Chu, W. T. Tai, K. Ichikawa, P. J. Chen and A. L. Cheng, Br. J. Pharmacol., 2013, 168, 658-672.

42 R. Gedaly, P. Angulo, J. Hundley, M. F. Daily, C. Chen, A. Koch and B. M. Evers, Anticancer Res., 2010, 30, 49514958.

43 C. H. Chen, M. C. Chen, J. C. Wang, A. C. Tsai, C. S. Chen, J. P. Liou, S. L. Pan and C. M. Teng, Clin. Cancer Res., 2014, 20, 1274-1287.

44 A. X. Zhu, O. Rosmorduc, T. R. Evans, P. J. Ross, A. Santoro, F. J. Carrilho, J. Bruix, S. Qin, P. J. Thuluvath, J. M. Llovet, M. A. Leberre, M. Jensen, G. Meinhardt and Y. K. Kang, J. Clin. Oncol., 2015, 33, 559-566.

45 P. Newell, S. Toffanin, A. Villanueva, D. Y. Chiang, B. Minguez, L. Cabellos, R. Savic, Y. Hoshida, K. H. Lim, P. Melgar-Lesmes, S. Yea, J. Peix, K. Deniz, M. I. Fiel, S. Thung, C. Alsinet, V. Tovar, V. Mazzaferro, J. Bruix, S. Roayaie, M. Schwartz, S. L. Friedman and J. M. Llovet, J. Hepatol., 2009, 51, 725-733. 
46 J. J. Gao, Z. Y. Shi, J. F. Xia, Y. Inagaki and W. Tang, World J. Gastroenterol., 2015, 21, 12059-12070.

47 M. Ouattara, D. Sissouma, M. W. Kone, H. E. Menan, S. A. Toure and L. Ouattara, Trop. J. Pharm. Res., 2011, 10, 767-775.

48 V. M. Reddy and K. R. Reddy, Chin. Chem. Lett., 2010, 21, 1145-1148.

49 B. Mathew, J. Suresh and D. Vinod, Med. Chem. Res., 2013, 22, 3911-3917.

50 H. B. Woo, Y. W. Eom, K. S. Park, J. Ham, C. M. Ahn and S. Lee, Bioorg. Med. Chem. Lett., 2012, 22, 933-936.

51 H. M. Refaat, Eur. J. Med. Chem., 2010, 45, 2949-2956.

52 M. Azam, A. A. Khan, S. I. Al-Resayes, M. S. Islam, A. K. Saxena, S. Dwivedi, J. Musarrat, A. Trzesowska-
Kruszynska and R. Kruszynski, Spectrochim. Acta, Part A, 2015, 142, 286-291.

53 M. E. Hayes, G. A. Wallace, P. Grongsaard, A. Bischoff, D. M. George, W. Y. Miao, M. J. McPherson, R. H. Stoffel, D. W. Green and G. P. Roth, Bioorg. Med. Chem. Lett., 2008, 18, 1573-1576.

54 S. Mehboob, J. H. Song, K. E. Hevener, P. C. Su, T. Boci, L. Brubaker, L. Truong, T. Mistry, J. P. Deng, J. L. Cook, B. D. Santarsiero, A. K. Ghosh and M. E. Johnson, Bioorg. Med. Chem. Lett., 2015, 25, 1292-1296.

55 A. Sharma, V. Luxami and K. Paul, Bioorg. Med. Chem. Lett., 2013, 23, 3288-3294.

56 J. R. Hwu, M. H. Hsu and R. C. Huang, Bioorg. Med. Chem. Lett., 2008, 18, 1884-1888. 